\title{
Current Perspectives on Maternal Influenza Immunization
}

\author{
Annette K. Regan ${ }^{1,2}$ - Siri E. Håberg ${ }^{3}$. Deshayne B. Fell ${ }^{4,5}$ \\ Published online: 12 November 2019 \\ (C) Springer Nature Switzerland AG 2019
}

\begin{abstract} the infant in the first few months of life. benefits of influenza vaccination.

\section{Introduction}

Influenza is a potentially serious respiratory illness, resulting in an estimated 291-645,000 deaths worldwide every year [1]. Although infection typically results in a self-limiting illness, severe cases can result in potentially life-threatening complications requiring hospitalization and intensive treatment. Such complications can include pneumonia, myocarditis, encephalitis, acute respiratory distress syndrome, respiratory failure,
\end{abstract}

Purpose of Review Pregnant women and young infants are more likely to experience severe complications associated with influenza infection and are at increased risk of hospitalization. Influenza vaccination during pregnancy produces antibodies which protect the mother against infection, and due to transplacental transfer of maternal antibodies before birth, it also protects

Recent Findings In many countries, influenza vaccination is recommended during pregnancy to protect mothers and their infants. In fact, influenza vaccine is the most widely used vaccine in pregnancy globally. When administered during pregnancy, the vaccine has been shown to be safe and effective for both mothers and their infants. Despite the health benefits, acceptance of influenza vaccine is low during pregnancy, indicating many women and infants are not protected against influenza.

Summary Concerted efforts are needed globally to improve the proportion of women and young infants who receive the health

Keywords Influenza vaccines $\cdot$ Influenza $\cdot$ Maternal vaccination $\cdot$ Pregnant women $\cdot$ Infant health

This article is part of the Topical Collection on Vaccines in Pregnant Women

Annette K. Regan

a_regan@tamu.edu

1 School of Public Health, Texas A\&M University, 212 Adriance Lab Rd. 1266 TAMU, College Station, TX 77843-1266, USA

2 Fielding School of Public Health, University of California Los Angeles, Los Angeles, CA, USA

3 Centre for Fertility and Health, Norwegian Institute of Public Health, Oslo, Norway

4 School or Epidemiology and Public Health, University of Ottawa, Ottawa, ON, Canada

5 Children's Hospital of Eastern Ontario (CHEO) Research Institute, Ottawa, ON, Canada sepsis, or death [2]. Certain individuals, in particular pregnant women and young infants, are at higher risk of developing serious complications including death.

\section{Burden of Influenza in Pregnant Women and Young Infants}

Numerous studies have observed a higher risk of morbidity and mortality among pregnant women compared with the nonpregnant adult population during influenza pandemics and seasonal epidemics [3, 4]. Immunological, anatomical, and hemodynamic changes induced by pregnancy are believed to predispose pregnant women to a higher risk of severe illness [5]. The anatomical and physiological changes in pregnancy present challenges to clearing viral infections, including a shift from cell-mediated immunity to humoral immunity, increased progesterone and glucocorticoids, increased heart rate, stroke volume, and oxygen consumption, as well as deceased lung capacity $[4,6]$. Animal studies have shown that altered inflammatory responses in response to influenza infection can lead to increased maternal morbidity, as well as increased risk of preterm labor, impaired fetal growth, and fetal mortality [7]. 
Several studies employing self-controlled methods have demonstrated greater severity of influenza illness during pregnancy. Ohfuji et al. [8] showed that across four influenza seasons, pregnant women were 2 to 4 times more likely to be hospitalized with respiratory illness during the influenza season compared with nonpregnant women. Similar estimates were reported in a previous Canadian study by Dodds et al. [9] that showed risk of respiratory hospitalization increases as pregnancy progresses, with the greatest increase in risk occurring in the third trimester. Among women with chronic medical conditions, the risk of hospitalization in the third trimester was 7 times greater compared with nonpregnant women [9]. Recent data from Spain indicate that influenza infection is also associated with increased rates of outpatient visits during the first or second trimester and the highest rates of hospitalization occur during the third trimester [10]. Estimates of the incidence of hospitalization with laboratory-confirmed influenza infection range from 0.04 to 7.7 cases per 10,000 pregnancies, with incidence of infection ranging from 487 to 1097 cases per 10,000 pregnancies [11]. Early initiation of antiviral treatment has been shown to reduce length of stay in hospital for pregnant women with laboratory-confirmed influenza during pandemics [12] and seasonal epidemics [13].

In addition to directly impacting maternal health, severe influenza illness is also associated with an increased risk of pregnancy complications $[6,12]$ and adverse fetal outcomes $[14,15]$. A recent systematic review concluded that severe 2009 pandemic A/H1N1 influenza illness (i.e., influenza illness requiring hospitalization) was associated with increased risk of preterm birth and fetal death [14]. A Canadian study showed that women with chronic medical conditions who were infected with 2009 pandemic A/H1N1 influenza experienced higher rates of spontaneous preterm birth [16]. During previous pandemics, several studies highlighted an increased risk of fetal death and other adverse events including preterm birth and low birthweight associated with pandemic infection during pregnancy $[4,15]$. In the most recent pandemic, the risk of fetal death was increased 2-fold for women who were infected with pandemic influenza $\mathrm{A} / \mathrm{H} 1 \mathrm{~N} 1$ during pregnancy [15]. Additional studies have also suggested women infected with pandemic influenza may be at higher risk of having a small-for-gestational-age infant [17]. The severity of maternal illness is likely to play an important role in the impact on fetal health, with more severe illnesses more likely to have adverse impacts [14]. While increased risk of severe illness and adverse outcomes has been observed during all trimesters of pregnancy, risk seems to be most pronounced in the third trimester of pregnancy $[6,12]$.

In the first months after birth, infants are especially susceptible to severe influenza illness due to the immaturity of their immune systems. Newborns have limited antibodies to protect against influenza infection [18••]. Young infants are at increased risk of influenza-associated complications and have been shown to experience the highest rates of hospitalization $[19,20]$ and death [21] compared with older children. Among infants hospitalized with influenza during the first year of life, $35 \%$ will require admission to an intensive care unit, and 1 in every 350 dies [22]. Because of the immature immune system in newborns, vaccines do not trigger adequate immune response and have not been shown to be effective in preventing influenza in young infants [23]. There is currently no licensed influenza vaccine for infants younger than 6 months. Beginning in the second trimester of pregnancy, antibodies cross the placenta from mother to fetus [24, 25]. These maternal antibodies act as nature's way of protecting young infants against the disease targeted by the antibody [26]. Vaccination in pregnancy boosts the concentration of vaccine-derived antibodies in maternal sera, and as a result, increases the transplacental transfer of maternal antibodies [27]. These maternally produced antibodies can offer protection to the infant in the first 6 months of life [28・,29, 30, 31・,32]. In the absence of primary vaccination strategies, maternal vaccination produces antibodies against influenza which are transferred to the infant during pregnancy, offering the optimal method of protection against potentially severe illness during infancy [28• 33].

\section{Historical Experience}

Since as early as 1960 in the United States (US), routine influenza immunization has been recommended to pregnant women [34, 35]. During the 1957 influenza A/H2N2 pandemic (also known as the "Asian Flu"), high mortality rates were observed, with 1.1 million deaths worldwide [36]. As a result of the excess deaths observed among those with chronic medical conditions, older adults, and pregnant women during the pandemic, the US Public Health Service made a recommendation to routinely immunize these priority groups [35]. To our knowledge, this was the first formal recommendation of influenza vaccines to pregnant women.

Following the 1957 pandemic, an estimated $>100,000$ US pregnant women received an influenza vaccine between 1959 and 1965 [37]. The US Collaborative Perinatal Project provided the earliest insights on maternal influenza vaccination. This prospective cohort study of maternal and childhood health aimed to recruit 50,000 pregnant women across 12 US clinical sites [38]. Between 1959 and 1966, the US Collaborative Perinatal Project followed up the children of 34,846 women, $2291(6 \%)$ of whom had received influenza vaccine during their pregnancy. After evaluating outcomes in the children, the investigators found no evidence for an increase in stillbirth, congenital malformations, or neurodevelopmental disabilities associated with influenza vaccination [39]. This was the first major report on safety of influenza vaccination during pregnancy and the largest study of vaccinated pregnant women at the time. 
In 1965, after considering the limited evidence of an increased risk of severe influenza-related disease in the general obstetrical population since the 1957-1958 influenza pandemic, the US Advisory Committee on Immunization Practice (ACIP) adjusted the national influenza vaccine recommendation to include only pregnant women with comorbid conditions known to predispose them to increased risk of severe disease [40]. These guidelines did not mention at what stage of pregnancy vaccination should occur [40]. In 1995, ACIP recommended that pregnant women with comorbid conditions receive influenza vaccine at any stage of pregnancy [41]. In 2004, ACIP expanded the recommendation to include healthy pregnant women with no comorbid conditions [42]. Today, influenza immunization is considered an essential component of prenatal care in the US and many other high-income countries [43-46], although some variation to these recommendations exists. For example, several European countries recommend vaccination after the first trimester rather than during any stage of pregnancy [47]. In the years immediately following these recommendations in the US, uptake of influenza vaccine during pregnancy remained low. US estimates show that between 10 and $14 \%$ of pregnant women were vaccinated between 1997 and 2005 [48, 49]. During this time, low immunization rates were linked to limited knowledge and implementation of the ACIP recommendations - fewer than half of obstetric providers reported recommending or providing influenza vaccine to pregnant women [48, 50].

It was not until the 2009 influenza A/H1N1 pandemic that the demand for and use of influenza vaccines during pregnancy dramatically increased. As the pandemic unfolded between March and June 2009, it became apparent that pregnant women were a high-risk group for severe illness [12]. In April 2009, the US Centers for Disease Control and Prevention (CDC) first reported the identification of novel influenza A virus infection in two young children [12]. The World Health Organization (WHO) declared influenza A/H1N1 a public health emergency of international concern on April 25 [51]. By the end of May, laboratory-confirmed cases were identified in 53 countries and 99 deaths had occurred [52], and by August, all continents were affected [53]. It was noted during the early stages of the pandemic that pregnant women appeared to be at higher risk of admission to ICU and death $[54,55]$, and by the end of the pandemic, pregnant women ultimately accounted for $5 \%$ of the total deaths [12].

Early in the pandemic, it was shown that the seasonal influenza vaccine did not offer protection against the pandemic virus [56], and a monovalent vaccine was developed and rapidly introduced. In July 2009, the US ACIP recommended that pregnant women and other high-risk groups be targeted for pandemic influenza immunization. During the pandemic in the US, it is estimated that $47 \%$ of pregnant women received a 2009 H1N1 vaccine [57]. The pandemic represented a shift in immunization acceptance, resulting in an increase in influenza vaccination rates. Several countries have reported sustained higher immunization rates among pregnant women during the post-pandemic period; however, the increase in uptake remains slow [58-62].

As of 2012, the WHO lists pregnant women as the highest priority group for countries considering initiation or expansion of their seasonal influenza vaccine campaigns [63]. At the last evaluation in 2014 , it was estimated that $42 \%$ of WHO Member States had policies recommending routine immunization of pregnant women against influenza [64]. It is almost certain that the number of countries has increased since then. As the importance and awareness of the health benefits of vaccination during pregnancy continue to increase, it is likely that uptake will continue to improve.

\section{Safety and Effectiveness}

Over the past two decades, the safety and effectiveness of influenza vaccination during pregnancy have been well investigated. The safety of vaccine administration has been confirmed in randomized controlled trials [29, 31•, 65-68], observational cohort studies [15, 16, 69-86], and post-licensure safety surveillance studies [87, 88, 89•, 90, 91]. Post-licensure surveillance data have shown that pregnant women report similar or fewer adverse events following influenza immunization compared with nonpregnant women of the same age [88]. Approximately 1 in 10 pregnant women reports a common, expected adverse event (e.g., local reaction, swelling, fatigue), and fewer than $3 \%$ report fever post-vaccination [87, 89•, 91, 92]. Similar rates of adverse events are reported by nonpregnant women of the same age, indicating pregnancy does not increase the risk of adverse events following immunization [88]. Although live attenuated influenza vaccines (LAIV) are contraindicated during pregnancy due to a hypothetical risk posed to the fetus, inadvertent administration of LAIV during pregnancy occurs infrequently. Post-licensure safety monitoring studies evaluating pregnancy administration of LAIV have not observed serious adverse events [93].

A number of comparative observational studies have confirmed the safety of influenza vaccination in terms of fetal health. Since 2015, seven systematic reviews have been published evaluating the association between influenza vaccination during pregnancy and subsequent birth outcomes [92, 94-99]. These reviews summarize data from more than 100,000 pregnancies and have all shown that vaccination during pregnancy is safe in terms of preterm birth, low birthweight, small-for-gestational-age, congenital anomalies, spontaneous abortion, and stillbirth [99]. Three large retrospective cohort studies have evaluated the safety of maternal vaccination in relation to childhood health outcomes, finding no increase in the risk of pediatric hospitalization [100], 
autism spectrum disorder [101], or the development of immune-related and non-immune-related pediatric outcomes $[102 \cdot]$.

The most recent systematic review noted several gaps in our knowledge of the safety of influenza vaccination during pregnancy [99]. First, the majority of studies include women vaccinated in the second or third trimester [99, 103••]. Studies from countries recommending influenza vaccination at any time in pregnancy, including first trimester, have not found an increased risk of congenital malformations, stillbirth, neonatal death, or preterm delivery [104, 105]. However, the limited evidence on first trimester vaccination has contributed to conservative immunization guidelines in some European countries, where vaccination is recommended in the second or third trimester of pregnancy [47]. Further studies evaluating the safety and benefits of influenza vaccination during the first trimester of pregnancy would be informative to international vaccine policy. Second, relatively few studies have been able to assess the impact of influenza vaccination during pregnancy on the risk of spontaneous abortion. Despite numerous studies evaluating birth outcomes, a small number of studies (including $<7000$ pregnancies) have evaluated spontaneous abortion [99]. Furthermore, the studies that have been conducted are all prone to left truncation bias $[106,107]$, due to pregnancy losses that occur at early gestational ages which are unrecognized or unreported. While the majority of studies that have been conducted have found no increase in the risk of spontaneous abortion associated with prenatal influenza vaccination $[78,84,85,108,109]$, a recent case-control study identified a possible increase in the risk of spontaneous abortion, particularly among those who received a 2009 pandemic A/H1N1containing vaccine in the season prior to becoming pregnant [110]. Although subsequent replication of this study in a different time period and with a larger sample size identified no association between influenza vaccination and spontaneous abortion [111], in combination with the biases present in existing research, this study highlights the need for more rigorous research of spontaneous abortion and maternal vaccination. Finally, with the introduction of pertussis vaccine recommendations in several countries and new vaccines on the horizon [28•], monitoring the safety of concomitant vaccine administration and repeat administration may be warranted.

In addition to the evidence supporting safety, influenza vaccination during pregnancy has been shown to be effective, both in terms of preventing maternal and infant infection. Effectiveness estimates vary, depending on the influenza season of the investigation and the study methods employed. The strongest evidence has been generated by the "Mother's Gift" randomized clinical trial conducted in 2004 in Bangladesh [29] and subsequent trials in Nepal, Mali, and South Africa $[28 \bullet, 30,31 \bullet, 32]$. The initial trial, including 164 infants, showed that influenza vaccination during pregnancy was $63 \%$ efficacious in preventing laboratory-confirmed influenza in infants [29]. The subsequent trials showed that maternal vaccination was between $30 \%$ (Nepal) [31 $[$ and $49 \%$ (South Africa) [32] efficacious against laboratory-confirmed infant influenza compared with controls. Several of these same trials also indicated that vaccination during pregnancy was between 50 and $70 \%$ efficacious in preventing laboratory-confirmed infection among pregnant women [30,32].

Observational studies of laboratory-confirmed influenza have supported the effectiveness of influenza vaccine in preventing influenza for both mothers and infants. Between 2000 and 2009, a matched case-control study by Benowitz et al. [112] estimated that influenza vaccination during pregnancy was $91 \%$ effective in reducing the risk of laboratoryconfirmed influenza hospitalization among infants. A subsequent UK population-based study showed that influenza vaccination was $71 \%$ effective in preventing infant infection and $64 \%$ effective in preventing infant hospitalization [113]. More recently, a Danish study reported seasonal influenza vaccine was $57 \%$ effective in preventing laboratory-confirmed influenza in infants < 6-month old during the 2010 through 2016 influenza seasons [114]. Estimates have been slightly lower for maternal protection associated with vaccination. A casecontrol study in two US states showed that influenza vaccination during pregnancy was associated with a $27-57 \%$ reduction in laboratory-confirmed influenza during pregnancy during the 2010-2011 and 2011-2012 influenza seasons [115]. A recent international cohort study which included data from four high-income countries showed that influenza vaccines were $40 \%$ effective in preventing laboratory-confirmed influenza hospitalization of pregnant women between 2010 and 2016 [116].

Several other studies with non-specific outcomes, such as all-cause acute respiratory infections, have also demonstrated the effectiveness of influenza vaccination during pregnancy. Two Australian studies have shown that maternal vaccination was associated with a $65 \%$ reduction in maternal hospitalization with acute respiratory infection [117] and a 25\% reduction in infant hospitalization [118]. In Japan, a study of selfreported influenza diagnosis showed that vaccination was $61 \%$ effective in preventing infant infection [119]. These estimates align with the $43 \%$ reduction in all-cause acute lower respiratory infections observed in some clinical trials [120]. However, it is worth mentioning that several observational studies have failed to identify measurable effectiveness of maternal vaccination [121-123].

In many countries, influenza vaccination is recommended during any trimester of pregnancy; however, limited data have evaluated the effectiveness of influenza vaccination by the trimester of vaccination. A recently published systematic review of immunological studies reported a 1.3 -fold greater geometric mean fold increase in maternal sera and 1.2-fold greater geometric mean titer (GMT) in cord blood among women vaccinated in the third trimester when compared with 
the second trimester [103••]. There were insufficient data to perform comparisons of the immunogenicity of vaccination during the first trimester [103••]. Despite this difference in immunogenicity, a recently published clinical trial found that vaccine efficacy against maternal and infant disease does not vary by gestational age at vaccination [18••]. Several observational studies have considered the effectiveness of influenza vaccination by trimester of pregnancy at vaccine administration. A recent CDC-led study estimated that influenza vaccination during pregnancy was $55 \%$ effective in preventing severe laboratory-confirmed maternal illness when the vaccine was administered in the first or second trimester, and offered no significant effectiveness when administered in the third trimester [116]. An observational study from Australia compared vaccine effectiveness by trimester of vaccination and identified a 33\% reduction in all-cause acute respiratory infection hospitalization of infants for vaccination in the third trimester, but no significant reduction when the vaccine was administered earlier in pregnancy [118]. Further evaluation of the effectiveness of vaccination by trimester with respect to both maternal and infant protection is warranted.

\section{Challenges to Widescale Implementation}

Despite the evidence supporting the benefits of maternal vaccination to mother and infant, challenges remain on widescale implementation. Coverage of influenza vaccines among pregnant women has continued to increase in high-income countries [58-60, 124]; however, no country is currently meeting the US Healthy People 2020 goal of $80 \%$ coverage [125]. Major barriers to influenza immunization cited by pregnant women include concerns regarding the safety of vaccine administration [126-129], a perception that vaccination is not necessary during pregnancy [127-129], and lack of recommendation by a healthcare provider [127, 129]. In fact, several studies have identified a healthcare provider recommendation as the strongest and most consistent predictor of receipt of influenza vaccine during pregnancy [130]. As a result, recent interventions for improving vaccine uptake have targeted not only pregnant women but also their healthcare providers [131].

Safety concerns impact community acceptance of vaccines during pregnancy [129] and complicate the implementation of clinical trials for the development of vaccines for pregnant women [132]. Historically, pregnant women and their offspring have been excluded from vaccine research; several studies have reported reluctance on the part of regulators, healthcare providers, and participants to include pregnant women in vaccine clinical trials [132, 133]. For example, while $75 \%$ of women are willing to accept the recently developed respiratory syncytial virus (RSV) vaccine during pregnancy if it is approved and routinely recommended, just 29\% of pregnant women are willing to accept the candidate RSV vaccine as part of a trial [134]. Because clinical trials form the basis for the safety information included with vaccine packaging, the limited availability of clinical trial data results in language in the package insert which contradicts clinical recommendations can lead to hesitancy on the part of health care providers to recommend vaccination to their pregnant patients [135]. Limited dissemination of clear information regarding vaccine safety for some vaccines has been identified as barriers to expanding maternal immunization programs [136, 137]. The hesitancy to include pregnant women in clinical trials may be changing, as several recent surveys have shown that women are willing to consider participating in new vaccine trials for group B streptococcus and Zika virus vaccines [138-140].

Several strategies have been proposed for encouraging improved implementation of maternal influenza vaccination programs in high-income settings. These include developing and executing provider-based interventions to encourage patientprovider interaction and communication about maternal vaccination, providing nudge-based interventions such as provider prompts to recommend vaccination, reducing or removing financial barriers to vaccination, and increasing access to vaccines during pregnancy at point of prenatal care [141]. However, limited high-quality evidence from randomized controlled trials is available [142] and the few trials that have been conducted provide conflicting results [143-145]. Additional high-quality investigations are needed to further evaluate interventions for improving influenza vaccination rates among pregnant women.

In a more global context, there are additional challenges facing the implementation of maternal influenza vaccination programs. Widescale implementation requires strong health information systems to routinely monitor vaccine safety [137]. Population-based local data to document baseline rates of adverse perinatal events and passive and active vaccine safety surveillance systems are needed. This can be a particular challenge in low and middle-income countries (LMICs), where population-based data and routine surveillance systems may be more limited [146, 147]. In addition, definitions and ascertainment of perinatal outcomes vary dramatically in different parts of the world [133]. To address this heterogeneity, recent efforts by the Brighton Collaboration's Global Alignment of Immunization Safety Assessment in Pregnancy (GAIA) project have resulted in the development of global standards for case definitions of adverse events following immunization during pregnancy. Recent evidence suggests these case definitions are both feasible and reliable in LMIC settings [148].

In addition to vaccine promotion and acceptance, more practical challenges exist, including seasonal vaccine procurement, expansion of immunization services to antenatal care settings, and financial barriers to widescale vaccine purchasing. Access to vaccines in LMICs is a major challenge, with 
more variation in access to antenatal care and greater obstacles to obtaining funding, ensuring cold chain and managing vaccine distribution and storage [149]. Routine vaccination recording and infectious disease surveillance data are needed to establish the local burden of infant and maternal influenza [149], and to provide data for studies of vaccine effectiveness and safety. Such information is rarely available in LMICs, which makes requisite economic evaluation and subsequent funding decisions difficult. Despite global evidence supporting the benefits to mother and infant, lack of available country-level data leads to the underestimation of burden and poor awareness of the need for maternal influenza vaccination in LMICs [150].

\section{Conclusions}

Influenza vaccination during pregnancy protects the mother and infant from influenza, severe complications, and death. Maternal immunization with influenza vaccine is recommended globally, with many countries currently implementing policies to promote vaccines to pregnant women. Although there are challenges to widescale implementation of these policies, these challenges can be addressed through informed and coordinated vaccine promotion. Given the evidence supporting the safety and effectiveness of maternal influenza vaccination, concerted effort to expand the use of influenza vaccines during pregnancy over the next decade is likely to have major health benefits for mothers and infants globally.

Funding Information This work was partly funded by the Norwegian Research council's Centre's of Excellence funding scheme (\#262700).

\section{Compliance With Ethical Standards}

Conflict of Interest The authors declare that they have no conflict of interest.

Human and Animal Rights and Informed Consent This article does not contain any studies with human or animal subjects performed by any of the authors.

\section{References}

Papers of particular interest, published recently, have been highlighted as:

- Of importance

•- Of major importance

1. Iuliano AD, Roguski KM, Chang HH, Muscatello DJ, Palekar R, Tempia S, et al. Estimates of global seasonal influenza-associated respiratory mortality: a modelling study. Lancet. 2018:391(10127):1285-300. https://doi.org/10.1016/s01406736(17)33293-2.
2. CDC. Flu symptoms and complications. 2019. https://www.cdc. gov/flu/symptoms/symptoms.htm. Accessed August 142019.

3. Yudin MH. Risk management of seasonal influenza during pregnancy: current perspectives. Int J Womens Health. 2014;6:681-9. https://doi.org/10.2147/IJWH.S47235.

4. Rasmussen SA, Jamieson DJ, Bresee JS. Pandemic influenza and pregnant women. Emerg Infect Dis. 2008;14(1):95-100. https:// doi.org/10.3201/eid1401.070667.

5. Jamieson DJ, Theiler RN, Rasmussen SA. Emerging infections and pregnancy. Emerg Infect Dis. 2006;12(11):1638-43. https:// doi.org/10.3201/eid1211.060152.

6. Raj RS, Bonney EA, Phillippe M. Influenza, immune system, and pregnancy. Reprod Sci. 2014;21(12):1434-51. https://doi.org/10. $1177 / 1933719114537720$.

7. Littauer EQ, Esser ES, Antao OQ, Vassilieva EV, Compans RW, Skountzou I. H1N1 influenza virus infection results in adverse pregnancy outcomes by disrupting tissue-specific hormonal regulation. PLoS Pathog. 2017;13(11):e1006757. https://doi.org/10. 1371/journal.ppat.1006757.

8. Ohfuji S, Deguchi M, Tachibana D, Koyama M, Takagi T, Yoshioka T, et al. Estimating influenza disease burden among pregnant women: application of self-control method. Vaccine. 2017;35(36):4811-6. https://doi.org/10.1016/j.vaccine.2017.07. 006.

9. Dodds L, McNeil SA, Fell DB, Allen VM, Coombs A, Scott J, et al. Impact of influenza exposure on rates of hospital admissions and physician visits because of respiratory illness among pregnant women. CMAJ. 2007;176(4):463-8. https://doi.org/10.1503/ cmaj.061435.

10. Vilca LM, Verma A, Bonati M, Campins M. Impact of influenza on outpatient visits and hospitalizations among pregnant women in Catalonia, Spain. J Infect. 2018;77(6):553-60. https://doi.org/ 10.1016/j.jinf.2018.06.015.

11. Katz MA, Gessner BD, Johnson J, Skidmore B, Knight M, Bhat $\mathrm{N}$, et al. Incidence of influenza virus infection among pregnant women: a systematic review. BMC Pregnancy Childbirth. 2017;17(1):155-12. https://doi.org/10.1186/s12884-017-1333-5.

12. Siston AM, Rasmussen SA, Honein MA, Fry AM, Seib K, Callaghan WM, et al. Pandemic 2009 influenza A(H1N1) virus illness among pregnant women in the United States. JAMA. 2010;303(15):1517-25. https://doi.org/10.1001/jama.2010.479.

13. Oboho IK, Reed C, Gargiullo P, Leon M, Aragon D, Meek J, et al. Benefit of early initiation of influenza antiviral treatment to pregnant women hospitalized with laboratory-confirmed influenza. J Infect Dis. 2016;214(4):507-15. https://doi.org/10.1093/infdis/ jiw033.

14. Fell DB, Savitz DA, Kramer MS, Gessner BD, Katz MA, Knight $\mathrm{M}$, et al. Maternal influenza and birth outcomes: systematic review of comparative studies. BJOG. 2017;124(1):48-59. https://doi. org/10.1111/1471-0528.14143.

15. Håberg SE, Trogstad L, Gunnes N, Wilcox AJ, Gjessing HK, Samuelsen SO, et al. Risk of fetal death after pandemic influenza virus infection or vaccination. New Engl J Med. 2013;368(4): 333-40. https://doi.org/10.1056/NEJMoa1207210.

16. Fell DB, Platt RW, Basso O, Wilson K, Kaufman JS, Buckeridge DL, et al. The relationship between 2009 pandemic H1N1 influenza during pregnancy and preterm birth: a population-based cohort study. Epidemiology. 2018;29(1):107-16. https://doi.org/10. 1097/ede.0000000000000753.

17. Hansen C, Desai S, Bredfeldt C, Cheetham C, Gallagher M, Li DK, et al. A large, population-based study of 2009 pandemic influenza A virus subtype H1N1 infection diagnosis during pregnancy and outcomes for mothers and neonates. J Infect Dis. 2012;206(8):1260-8. https://doi.org/10.1093/infdis/jis488.

18.• Katz J, Englund JA, Steinhoff MC, Khatry SK, Shrestha L, Kuypers $\mathrm{J}$, et al. Impact of timing of influenza vaccination in 
pregnancy on transplacental antibody transfer, influenza incidence, and birth outcomes: a randomized trial in rural Nepal. Clin Infect Dis. 2018;67(3):334 40. https://doi.org/10.1093/cid/ ciy090 Authors report evidence from clinical trial evaluating cord blood antibody titers by gestational age at influenza vaccine administration. Findings show that vaccine efficacy did not vary by gestational age at vaccination, which has implications for immunization policy and practice.

19. Neuzil KM, Mellen BG, Wright PF, Mitchel EF Jr, Griffin MR. The effect of influenza on hospitalizations, outpatient visits, and courses of antibiotics in children. New Engl J Med. 2000;342(4): 225-31. https://doi.org/10.1056/nejm200001273420401.

20. Poehling KA, Edwards KM, Weinberg GA, Szilagyi P, Staat MA, Iwane MK, et al. The underrecognized burden of influenza in young children. New Engl J Med. 2006;355(1):31-40. https:// doi.org/10.1056/NEJMoa054869.

21. Bhat N, Wright JG, Broder KR, Murray EL, Greenberg ME, Glover MJ, et al. Influenza-associated deaths among children in the United States, 2003-2004. New Engl J Med. 2005;353(24): 2559-67. https://doi.org/10.1056/NEJMoa051721.

22. Blyth CC, Macartney KK, Hewagama S, Senenayake S, Friedman ND, Simpson G, et al. Influenza epidemiology, vaccine coverage and vaccine effectiveness in children admitted to sentinel Australian hospitals in 2014: the Influenza Complications Alert Network (FluCAN). Euro Surveill. 2016;21(30). https://doi.org/ 10.2807/1560-7917.es.2016.21.30.30301.

23. MacDonald NE, McDonald JC. Canadian Paediatric Society ID, Immunization $\mathrm{C}$. The benefits of influenza vaccine in pregnancy for the fetus and the infant younger than six months of age. Paediatr Child Health. 2014;19(9):e121-e2.

24. Saji F, Samejima Y, Kamiura S, Koyama M. Dynamics of immunoglobulins at the feto-maternal interface. Rev Reprod. 1999;4(2): 81-9.

25. Malek A, Sager R, Kuhn P, Nicolaides KH, Schneider H. Evolution of maternofetal transport of immunoglobulins during human pregnancy. Am J Reprod Immunol. 1996;36(5):248-55.

26. Esposito S, Bosis S, Morlacchi L, Baggi E, Sabatini C, Principi N. Can infants be protected by means of maternal vaccination? Clin Microbiol Infect. 2012;18(Suppl 5):85-92. https://doi.org/10. 1111/j.1469-0691.2012.03936.x.

27. Calvert A, Jones CE. Placental transfer of antibody and its relationship to vaccination in pregnancy. Curr Opinion Infect Dis. 2017;30(3):268-73. https://doi.org/10.1097/qco. 0000000000000372 .

28. Omer SB. Maternal immunization. New Engl J Med. 2017;376(13):1256-67. https://doi.org/10.1056/ NEJMra1509044 Review article which provides a summary of the results of three recent clinical trials evaluating prenatal influenza vaccine efficacy against maternal and infant infection.

29. Zaman K, Roy E, Arifeen SE, Rahman M, Raqib R, Wilson E, et al. Effectiveness of maternal influenza immunization in mothers and infants. New Engl J Med. 2008;359(15):1555-64. https://doi. org/10.1056/NEJMoa0708630.

30. Tapia MD, Sow SO, Tamboura B, Teguete I, Pasetti MF, Kodio M, et al. Maternal immunisation with trivalent inactivated influenza vaccine for prevention of influenza in infants in Mali: a prospective, active-controlled, observer-blind, randomised phase 4 trial. Lancet Infect Dis. 2016;16(9):1026-35. https://doi.org/10.1016/ s1473-3099(16)30054-8.

31. Steinhoff MC, Katz J, Englund JA, Khatry SK, Shrestha L, Kuypers J, et al. Year-round influenza immunisation during pregnancy in Nepal: a phase 4, randomised, placebo-controlled trial. Lancet Infect Dis. 2017;17(9):981-9. https://doi.org/10.1016/ s1473-3099(17)30252-9 Results from this clinical trial suggest that influenza vaccination of pregnant women throughout the year would offer significant protection to pregnant women and their infants in subtropical regions, where influenza circulates year-round.

32. Madhi SA, Cutland CL, Kuwanda L, Weinberg A, Hugo A, Jones $\mathrm{S}$, et al. Influenza vaccination of pregnant women and protection of their infants. New Engl J Med. 2014;371(10):918-31. https:// doi.org/10.1056/NEJMoa1401480.

33. Marshall H, McMillan M, Andrews RM, Macartney K, Edwards $\mathrm{K}$. Vaccines in pregnancy: the dual benefit for pregnant women and infants. Hum Vaccin Immunother. 2016;12(4):848-56. https:// doi.org/10.1080/21645515.2015.1127485.

34. Jamieson DJ, Kissin DM, Bridges CB, Rasmussen SA. Benefits of influenza vaccination during pregnancy for pregnant women. Am J Obstet Gynecol. 2012;207(3 Suppl):S17-20. https://doi.org/10. 1016/j.ajog.2012.06.070.

35. Burney LE. Influenza immunization: statement. Public Health Rep. 1960;75(10):944.

36. Kilbourne ED. Influenza pandemics of the 20th century. Emerg Infect Dis. 2006;12(1):9-14. https://doi.org/10.3201/eid1201. 051254.

37. Englund JA. Maternal immunization with inactivated influenza vaccine: rationale and experience. Vaccine. 2003;21(24):3460-4. https://doi.org/10.1016/s0264-410x(03)00351-7.

38. Klebanoff MA. The Collaborative Perinatal Project: a 50-year retrospective. Paediatr Perinat Epidemiol. 2009;23(1):2-8. https://doi.org/10.1111/j.1365-3016.2008.00984.x.

39. Heinonen OP, Shapiro S, Monson RR, Hartz SC, Rosenberg L, Slone D. Immunization during pregnancy against poliomyelitis and influenza in relation to childhood malignancy. Int $\mathbf{J}$ Epidemiol. 1973;2(3):229-35. https://doi.org/10.1093/ije/2.3.229.

40. CDC. Recommendations for influenza immunization and control in the civilian population - 1965-66. MMWR Morb Mortal Wkly Rep. 1965;14(24):203-8.

41. CDC. Prevention and control of influenza recommendations of the Advisory Committee on Immunization Practices (ACIP). MMWR Morb Mortal Wkly Rep. 1995;44(Rr-3):1-22.

42. CDC. Prevention and control of influenza: recommendations of the Advisory Committee on Immunization Practices (ACIP). MMWR Morb Mortal Wkly Rep. 2004;53(Rr-6):1-40.

43. CDC. Prevention and control of seasonal influenza with vaccines: recommendations of the Advisory Committee on Immunization Practices - United States, 2019-20 influenza season. MMWR Morb Mortal Wkly Rep. 2019;68(3):1-21. https://doi.org/10. 15585/mmwr.rr6803a1.

44. RANZCOG. Influenza vaccination during pregnancy (and women planning pregnancy) C-Obs 45. 2017. https://ranzcog.edu.au/ RANZCOG_SITE/media/RANZCOG-MEDIA/Women\%27 s\% 20Health/Statement\%20and\%20guidelines/Clinical-Obstetrics/ Influenza-vaccination-in-pregnancy-(C-Obs-45)-Review-March2017.pdf?ext = .pdf. Accessed 6 September 2019.

45. ACOG. Influenza vaccination during pregnancy. ACOG Committee Opinion No. 732. Obstet Gynecol. 2018;131:e109 14.

46. PHAC. An Advisory Committee Statement (ACS) NAtional Advisory Committee on Immunization (NACI): canadian immunization guide chapter on influenza and statement of seaosnal influenza vaccine for 2019-20. 2019. https:/www.canada.ca/en/ public-health/services/publications/vaccines-immunization/ canadian-immunization-guide-statement-seasonal-influenzavaccine-2019-2020.html. Accessed 6 September 2019.

47. ECDC. Seasonal influenza vaccination in Europe: vaccination recommendations and coverage rates in the EU Member States for eight influenza seasons: 2007-2008 to 2014-15. Stockholm: ECDC; 2017. 
48. CDC. Influenza vaccination in pregnancy: practices among obstetrician-gynecologists-United States, 2003-04 influenza season. MMWR Morb Mortal Wkly Rep. 2005;54(41):1050-2.

49. Lu P, Bridges CB, Euler GL, Singleton JA. Influenza vaccination of recommended adult populations, U.S., 1989-2005. Vaccine. 2008;26(14):1786-93. https://doi.org/10.1016/j.vaccine.2008.01. 040 .

50. Schrag SJ, Fiore AE, Gonik B, Malik T, Reef S, Singleton JA, et al. Vaccination and perinatal infection prevention practices among obstetrician-gynecologists. Obstet Gynecol. 2003;101(4): 704-10.

51. WHO. Swine flu illness in the United States and Mexico - update 2. https://www.who.int/csr/don/2009_04_26/en/. Accessed August 122019

52. WHO. Influenza A(H1N1) - update 41. https://www.who.int/csr/ don/2009 05 29/en/. Accessed August 122019.

53. WHO. Pandemic (H1N1) 2009 - update 61. https://www.who.int/ csr/don/2009 08 12/en/. Accessed August 122019.

54. ANZIC Influenza Investigators and Australasian Maternity Outcomes Surveillance System. Critical illness due to 2009 A/H1N1 influenza in pregnant and postpartum women: population based cohort study. BMJ. 2010;340:c1279. https://doi.org/10. 1136/bmj.c1279.

55. CDC. Novel influenza A (H1N1) virus infections in three pregnant women - United States, April-May 2009. MMWR Morb Mortal Wkly Rep. 2009;58(18):497-500.

56. CDC. Serum cross-reactive antibody response to a novel influenza A (H1N1) virus after vaccination with seasonal influenza vaccine. MMWR Morb Mortal Wkly Rep. 2009;58(19):521-4.

57. CDC. Seasonal influenza and $2009 \mathrm{H} 1 \mathrm{~N} 1$ influenza vaccination coverage among pregnant women-10 states, 2009-10 influenza season. MMWR Morb Mortal Wkly Rep. 2010;59(47):1541-5.

58. CDC. Influenza vaccination coverage during pregnancy - selected sites, United States, 2005-06 through 2013-14 influenza vaccine seasons. MMWR Morb Mortal Wkly Rep. 2016;65(48):1370-3. https://doi.org/10.15585/mmwr.mm6548a3.

59. McCarthy EA, Pollock WE, Tapper L, Sommerville M, McDonald S. Increasing uptake of influenza vaccine by pregnant women post H1N1 pandemic: a longitudinal study in Melbourne, Australia, 2010 to 2014. BMC Pregnancy Childbirth. 2015;15: 53-7. https://doi.org/10.1186/s12884-015-0486-3.

60. Regan AK, Mak DB, Hauck YL, Gibbs R, Tracey L, Effler PV. Trends in seasonal influenza vaccine uptake during pregnancy in Western Australia: implications for midwives. Women Birth. 2016;29(5):423-9. https://doi.org/10.1016/j.wombi.2016.01.009.

61. Wiley KE, Massey PD, Cooper SC, Wood NJ, Ho J, Quinn HE, et al. Uptake of influenza vaccine by pregnant women: a crosssectional survey. Med J Aust. 2013;198(7):373-5.

62. Seo J, Lim J. Trends in influenza vaccination coverage rates in South Korea from 2005 to 2014: effect of public health policies on vaccination behavior. Vaccine. 2018;36(25):3666-73. https://doi. org/10.1016/j.vaccine.2018.05.024.

63. WHO. Vaccines against influenza WHO position paper November 2012. Wkly Epidemiol Rev. 2012;87(47):461-76.

64. Ortiz JR, Perut M, Dumolard L, Wijesinghe PR, Jorgensen P, Ropero AM, et al. A global review of national influenza immunization policies: analysis of the $2014 \mathrm{WHO} / \mathrm{UNICEF}$ Joint Reporting Form on immunization. Vaccine. 2016;34(45):5400 5. https://doi.org/10.1016/j.vaccine.2016.07.045.

65. Munoz FM, Jackson LA, Swamy GK, Edwards KM, Frey SE, Stephens I, et al. Safety and immunogenicity of seasonal trivalent inactivated influenza vaccines in pregnant women. Vaccine. 2018;36(52):8054-61. https://doi.org/10.1016/j.vaccine.2018.10. 088 .

66. Simoes EAF, Nunes MC, Carosone-Link P, Madimabe R, Ortiz JR, Neuzil KM, et al. Trivalent influenza vaccination randomized control trial of pregnant women and adverse fetal outcomes. Vaccine. 2019;37(36):5397-403. https://doi.org/10.1016/j. vaccine.2019.07.024.

67. Sumaya CV, Gibbs RS. Immunization of pregnant women with influenza A/New Jersey/76 virus vaccine: reactogenicity and immunogenicity in mother and infant. J Infect Dis. 1979;140(2): 141-6. https://doi.org/10.1093/infdis/140.2.141.

68. Steinhoff MC, Omer SB, Roy E, El Arifeen S, Raqib R, Dodd C, et al. Neonatal outcomes after influenza immunization during pregnancy: a randomized controlled trial. CMAJ. 2012;184(6): 645-53. https://doi.org/10.1503/cmaj.110754.

69. McHugh L, Andrews RM, Lambert SB, Viney KA, Wood N, Perrett KP, et al. Birth outcomes for Australian mother-infant pairs who received an influenza vaccine during pregnancy, 2012-2014: the FluMum study. Vaccine. 2017;35(10):1403-9. https://doi.org/ 10.1016/j.vaccine.2017.01.075

70. McHugh L, Marshall HS, Perrett KP, Nolan T, Wood N, Lambert $\mathrm{SB}$, et al. The safety of influenza and pertussis vaccination in pregnancy in a cohort of Australian mother-infant pairs, 20122015: the FluMum Study. Clin Infect Dis. 2019;68(3):402-8. https://doi.org/10.1093/cid/ciy517.

71. Regan AK, Moore HC, de Klerk N, Omer SB, Shellam G, Mak $\mathrm{DB}$, et al. Seasonal trivalent influenza vaccination during pregnancy and the incidence of stillbirth: population-based retrospective cohort study. Clin Infect Dis. 2016;62(10):1221-7. https://doi.org/ 10.1093/cid/ciw082.

72. Nordin JD, Kharbanda EO, Benitez GV, Nichol K, Lipkind H, Naleway A, et al. Maternal safety of trivalent inactivated influenza vaccine in pregnant women. Obstet Gynecol. 2013;121(3):519 25. https://doi.org/10.1097/AOG.0b013e3182831b83.

73. Nordin JD, Kharbanda EO, Vazquez-Benitez G, Lipkind H, Lee GM, Naleway AL. Monovalent H1N1 influenza vaccine safety in pregnant women, risks for acute adverse events. Vaccine. 2014;32(39):4985-92. https://doi.org/10.1016/j.vaccine.2014.07. 017.

74. Olsen SJ, Mirza SA, Vonglokham P, Khanthamaly V, Chitry B, Pholsena V, et al. The effect of influenza vaccination on birth outcomes in a cohort of pregnant women in Lao PDR, 20142015. Clin Infect Dis. 2016;63(4):487-94. https://doi.org/10. 1093/cid/ciw290.

75. Baum U, Leino T, Gissler M, Kilpi T, Jokinen J. Perinatal survival and health after maternal influenza $\mathrm{A}(\mathrm{H} 1 \mathrm{~N} 1)$ pdm09 vaccination: a cohort study of pregnancies stratified by trimester of vaccination. Vaccine. 2015;33(38):4850-7. https://doi.org/10.1016/j.vaccine. 2015.07.061.

76. Chavant F, Ingrand I, Jonville-Bera AP, Plazanet C, Gras-Champel V, Lagarce L, et al. The PREGVAXGRIP study: a cohort study to assess foetal and neonatal consequences of in utero exposure to vaccination against $\mathrm{A}(\mathrm{H} 1 \mathrm{~N} 1) \mathrm{v} 2009$ influenza. Drug Saf. 2013;36(6):455-65. https://doi.org/10.1007/s40264-013-0030-1.

77. Cleary BJ, Rice U, Eogan M, Metwally N, McAuliffe F. 2009 $\mathrm{A} / \mathrm{H} 1 \mathrm{~N} 1$ influenza vaccination in pregnancy: uptake and pregnancy outcomes - a historical cohort study. Eur J Obstet Gynecol Reprod Biol. 2014;178:163-8. https://doi.org/10.1016/j.ejogrb. 2014.04.015.

78. Heikkinen T, Young J, van Beek E, Franke H, Verstraeten T, Weil JG, et al. Safety of MF59-adjuvanted A/H1N1 influenza vaccine in pregnancy: a comparative cohort study. Am J Obstet Gynecol. 2012;207(3):177.e1-8. https://doi.org/10.1016/j.ajog.2012.07. 007.

79. Louik C, Kerr S, Van Bennekom CM, Chambers C, Jones KL, Schatz M, et al. Safety of the 2011-12, 2012-13, and 2013-14 seasonal influenza vaccines in pregnancy: preterm delivery and specific malformations, a study from the case-control arm of VAMPSS. Vaccine. 2016;34(37):4450-9. https://doi.org/10. 1016/j.vaccine.2016.06.078. 
80. Naleway AL, Irving SA, Henninger ML, Li DK, Shifflett P, Ball S, et al. Safety of influenza vaccination during pregnancy: a review of subsequent maternal obstetric events and findings from two recent cohort studies. Vaccine. 2014;32(26):3122-7. https://doi. org/10.1016/j.vaccine.2014.04.021.

81. Oppermann M, Fritzsche J, Weber-Schoendorfer C, KellerStanislawski B, Allignol A, Meister R, et al. A(H1N1)v2009: a controlled observational prospective cohort study on vaccine safety in pregnancy. Vaccine. 2012;30(30):4445-52. https://doi.org/ 10.1016/j.vaccine.2012.04.081.

82. Tavares F, Nazareth I, Monegal JS, Kolte I, Verstraeten T, Bauchau V. Pregnancy and safety outcomes in women vaccinated with an AS03-adjuvanted split virion H1N1 (2009) pandemic influenza vaccine during pregnancy: a prospective cohort study. Vaccine. 2011;29(37):6358-65. https://doi.org/10.1016/j.vaccine. 2011.04.114.

83. Omon E, Damase-Michel C, Hurault-Delarue C, Lacroix I, Montastruc JL, Oustric S, et al. Non-adjuvanted 2009 influenza A $(\mathrm{H} 1 \mathrm{~N} 1) \mathrm{v}$ vaccine in pregnant women: the results of a French prospective descriptive study. Vaccine. 2011;29(52):9649-54. https://doi.org/10.1016/j.vaccine.2011.10.034.

84. Chambers CD, Johnson D, Xu R, Luo Y, Louik C, Mitchell AA, et al. Risks and safety of pandemic H1N1 influenza vaccine in pregnancy: birth defects, spontaneous abortion, preterm delivery, and small for gestational age infants. Vaccine. 2013;31(44):502632. https://doi.org/10.1016/j.vaccine.2013.08.097.

85. Chambers CD, Johnson DL, Xu R, Luo YJ, Louik C, Mitchell AA, et al. Safety of the 2010-11, 2011-12, 2012-13, and 2013-14 seasonal influenza vaccines in pregnancy: birth defects, spontaneous abortion, preterm delivery, and small for gestational age infants, a study from the cohort arm of VAMPSS. Vaccine. 2016;34(37):4443-9. https://doi.org/10.1016/j.vaccine.2016.06. 054.

86. Zerbo O, Modaressi S, Chan B, Goddard K, Lewis N, Bok K, et al. No association between influenza vaccination during pregnancy and adverse birth outcomes. Vaccine. 2017;35(24):3186-90. https://doi.org/10.1016/j.vaccine.2017.04.074.

87. Regan AK, Blyth CC, Effler PV. Using SMS technology to verify the safety of seasonal trivalent influenza vaccine for pregnant women in real time. Med J Aust. 2013;199(11):744-6.

88. Regan AK, Tracey L, Blyth CC, Mak DB, Richmond PC, Shellam $\mathrm{G}$, et al. A prospective cohort study comparing the reactogenicity of trivalent influenza vaccine in pregnant and non-pregnant women. BMC Pregnancy Childbirth. 2015;15:61-7. https://doi.org/10. 1186/s12884-015-0495-2.

89. Regan AK, Tracey LE, Blyth CC, Richmond PC, Effler PV. A prospective cohort study assessing the reactogenicity of pertussis and influenza vaccines administered during pregnancy. Vaccine. 2016;34(20):2299-304. https://doi.org/10.1016/j.vaccine.2016. 03.084 Results from this prospective cohort study identified no increase in adverse events following influenza vaccine, given on its own or in combination with pertussis vaccine.

90. Carcione D, Blyth CC, Richmond PC, Mak DB, Effler PV. Safety surveillance of influenza vaccine in pregnant women. Austr N Z J Obstet Gynecol. 2013;53(1):98-9. https://doi.org/10.1111/ajo. 12034.

91. Stockwell MS, Cano M, Jakob K, Broder KR, GyamfiBannerman C, Castano PM, et al. Feasibility of text message influenza vaccine safety monitoring during pregnancy. Am J Prev Med. 2017;53(3):282-9. https://doi.org/10.1016/j.amepre. 2017.03.014.

92. Moro P, Baumblatt J, Lewis P, Cragan J, Tepper N, Cano M. Surveillance of adverse events after seasonal influenza vaccination in pregnant women and their infants in the Vaccine Adverse Event Reporting System, July 2010-May 2016. Drug Saf. 2017;40(2): 145-52. https://doi.org/10.1007/s40264-016-0482-1.
93. Haber P, Moro PL, Cano M, Lewis P, Stewart B, Shimabukuro TT. Post-licensure surveillance of quadrivalent live attenuated influenza vaccine United States, Vaccine Adverse Event Reporting System (VAERS), July 2013-June 2014. Vaccine. 2015;33(16): 1987-92. https://doi.org/10.1016/j.vaccine.2015.01.080.

94. Bratton KN, Wardle MT, Orenstein WA, Omer SB. Maternal influenza immunization and birth outcomes of stillbirth and spontaneous abortion: a systematic review and meta-analysis. Clin Infect Dis. 2015;60(5):e11-9. https://doi.org/10.1093/cid/ciu915.

95. Fell DB, Platt RW, Lanes A, Wilson K, Kaufman JS, Basso O, et al. Fetal death and preterm birth associated with maternal influenza vaccination: systematic review. BJOG. 2015;122(1):17-26. https://doi.org/10.1111/1471-0528.12977.

96. McMillan M, Porritt K, Kralik D, Costi L, Marshall H. Influenza vaccination during pregnancy: a systematic review of fetal death, spontaneous abortion, and congenital malformation safety outcomes. Vaccine. 2015;33(18):2108-17. https://doi.org/10.1016/j. vaccine.2015.02.068.

97. Polyzos KA, Konstantelias AA, Pitsa CE, Falagas ME. Maternal influenza vaccination and risk for congenital malformations: a systematic review and meta-analysis. Obstet Gynecol. 2015;126(5):1075-84. https://doi.org/10.1097/aog. 0000000000001068

98. Nunes MC, Aqil AR, Omer SB, Madhi SA. The effects of influenza vaccination during pregnancy on birth outcomes: a systematic review and meta-Analysis. Am J Perinatol. 2016;33(11): 1104-14. https://doi.org/10.1055/s-0036-1586101.

99. Giles ML, Krishnaswamy S, Macartney K, Cheng A. The safety of inactivated influenza vaccines in pregnancy for birth outcomes: a systematic review. Hum Vaccin Immunother. 2019;15(3):68799. https://doi.org/10.1080/21645515.2018.1540807.

100. Hviid A, Svanstrom H, Molgaard-Nielsen D, Lambach P. Association between pandemic influenza $\mathrm{A}(\mathrm{H} 1 \mathrm{~N} 1)$ vaccination in pregnancy and early childhood morbidity in offspring. JAMA Pediatr. 2017;171(3):239-48. https://doi.org/10.1001/ jamapediatrics.2016.4023.

101. Zerbo O, Qian Y, Yoshida C, Fireman BH, Klein NP, Croen LA. Association between influenza infection and vaccination during pregnancy and risk of Autism Spectrum Disorder. JAMA Pediatr. 2017;171(1):e163609. https://doi.org/10.1001/ jamapediatrics.2016.3609.

102. Walsh LK, Donelle J, Dodds L, Hawken S, Wilson K, Benchimol EI, et al. Health outcomes of young children born to mothers who received 2009 pandemic H1N1 influenza vaccination during pregnancy: retrospective cohort study. BMJ. 2019;366:14151. https:// doi.org/10.1136/bmj.14151 First cohort study to evaluate the risk of a range of pre-specified pediatric health outcomes associated with 2009 monovalent pandemic $A / H 1 N 1$ vaccination during pregnancy.

103.• Cuningham W, Geard N, Fielding JE, Braat S, Madhi SA, Nunes $\mathrm{MC}$, et al. Optimal timing of influenza vaccine during pregnancy: a systematic review and meta-analysis. Influenza Other Respir Viruses. 2019;13(5):438-52. https://doi.org/10.1111/irv.12649 Recent systematic review which highlights differences in the immunogenicity of influenza vaccine administered at different stages of pregnancy as observed in matenral sera and cord blood.

104. Kharbanda EO, Vazquez-Benitez G, Romitti PA, Naleway AL, Cheetham TC, Lipkind HS, et al. First trimester influenza vaccination and risks for major structural birth defects in offspring. $\mathrm{J}$ Pediatr. 2017;187:234-9.e4. https://doi.org/10.1016/j.jpeds.2017. 04.039 .

105. Sheffield JS, Greer LG, Rogers VL, Roberts SW, Lytle H, McIntire DD, et al. Effect of influenza vaccination in the first trimester of pregnancy. Obstet Gynecol. 2012;120(3):532-7. https://doi.org/10.1097/AOG.0b013e318263a278. 
106. Xu R, Luo Y, Chambers C. Assessing the effect of vaccine on spontaneous abortion using time-dependent covariates Cox models. Pharmacoepidemiol Drug Saf. 2012;21(8):844-50. https://doi.org/10.1002/pds.3301.

107. Schisterman EF, Cole SR, Ye A, Platt RW. Accuracy loss due to selection bias in cohort studies with left truncation. Paediatr Perinat Epidemiol. 2013;27(5):491-502. https://doi.org/10.1111/ ppe.12073.

108. Beau AB, Hurault-Delarue C, Vidal S, Guitard C, Vayssiere C, Petiot D, et al. Pandemic A/H1N1 influenza vaccination during pregnancy: a comparative study using the EFEMERIS database. Vaccine. 2014;32(11):1254-8. https://doi.org/10.1016/j.vaccine. 2014.01.021.

109. Pasternak B, Svanstrom H, Molgaard-Nielsen D, Krause TG, Emborg HD, Melbye M, et al. Vaccination against pandemic A/H1N1 2009 influenza in pregnancy and risk of fetal death: cohort study in Denmark. BMJ. 2012;344:e2794. https://doi.org/ 10.1136/bmj.e2794.

110. Donahue JG, Kieke BA, King JP, DeStefano F, Mascola MA, Irving SA, et al. Association of spontaneous abortion with receipt of inactivated influenza vaccine containing H1N1pdm09 in 201011 and 2011-12. Vaccine. 2017;35(40):5314-22. https://doi.org/ 10.1016/j.vaccine.2017.06.069.

111. CDC. Flu vaccination \& addressing concerns pregnatn women might have about flu vaccine safety. https:/www.cdc.gov/flu/ professionals/vaccination/vaccination-possible-safety-signal.html. Accessed 6 September 2019.

112. Benowitz I, Esposito DB, Gracey KD, Shapiro ED, Vázquez M. Influenza vaccine given to pregnant women reduces hospitalization due to influenza in their infants. Clin Infect Dis. 2010;51(12): 1355-61. https://doi.org/10.1086/657309.

113. Dabrera G, Zhao H, Andrews N, Begum F, Green H, Ellis J, et al. Effectiveness of seasonal influenza vaccination during pregnancy in preventing influenza infection in infants, England, 2013/14. Euro Surveill. 2014;19(45):20959. https://doi.org/10.2807/15607917.es2014.19.45.20959.

114. Molgaard-Nielsen D, Fischer TK, Krause TG, Hviid A. Effectiveness of maternal immunization with trivalent inactivated influenza vaccine in pregnant women and their infants. J Intern Med. 2019. https://doi.org/10.1111/joim.12947.

115. Thompson MG, Li DK, Shifflett P, Sokolow LZ, Ferber JR, Kurosky S, et al. Effectiveness of seasonal trivalent influenza vaccine for preventing influenza virus illness among pregnant women: a population-based case-control study during the 2010-2011 and 2011-2012 influenza seasons. Clin Infect Dis. 2014;58(4): 449-57. https://doi.org/10.1093/cid/cit750.

116. Thompson MG, Kwong JC, Regan AK, Katz MA, Drews SJ, Azziz-Baumgartner E, et al. Influenza vaccine effectiveness in preventing influenza-associated hospitalizations during pregnancy: a multi-country retrospective test negative design study, 20102016. Clin Infect Dis. 2019;68(9):1444-53. https://doi.org/10. 1093/cid/ciy737.

117. Regan AK, Klerk N, Moore HC, Omer SB, Shellam G, Effler PV. Effectiveness of seasonal trivalent influenza vaccination against hospital-attended acute respiratory infections in pregnant women: a retrospective cohort study. Vaccine. 2016;34(32):3649-56. https://doi.org/10.1016/j.vaccine.2016.05.032.

118. Regan AK, de Klerk N, Moore HC, Omer SB, Shellam G, Effler $\mathrm{PV}$. Effect of maternal influenza vaccination on hospitalization for respiratory infections in newborns: a retrospective cohort study. Pediatr Infect Dis J. 2016;35(10):1097-103. https://doi.org/10. 1097/inf.0000000000001258.

119. Ohfuji S, Deguchi M, Tachibana D, Koyama M, Takagi T, Yoshioka T, et al. Protective effect of maternal influenza vaccination on influenza in their infants: a prospective cohort study. J
Infect Dis. 2018;217(6):878-86. https://doi.org/10.1093/infdis/ jix629.

120. Nunes MC, Cutland CL, Jones S, Downs S, Weinberg A, Ortiz JR, et al. Efficacy of maternal influenza vaccination against all-cause lower respiratory tract infection hospitalizations in young infants: results from a randomized controlled trial. Clin Infect Dis. 2017;65(7):1066-71. https://doi.org/10.1093/cid/cix497.

121. France EK, Smith-Ray R, McClure D, Hambidge S, Xu S, Yamasaki $\mathrm{K}$, et al. Impact of maternal influenza vaccination during pregnancy on the incidence of acute respiratory illness visits among infants. Arch Pediatr Adolesc Med. 2006;160(12):127783. https://doi.org/10.1001/archpedi.160.12.1277.

122. Black SB, Shinefield HR, France EK, Fireman BH, Platt ST, Shay D. Effectiveness of influenza vaccine during pregnancy in preventing hospitalizations and outpatient visits for respiratory illness in pregnant women and their infants. Am J Perinatol. 2004;21(6):333-9. https://doi.org/10.1055/s-2004-831888.

123. Fell DB, Wilson K, Ducharme R, Hawken S, Sprague AE, Kwong $\mathrm{JC}$, et al. Infant respiratory outcomes associated with prenatal exposure to maternal $2009 \mathrm{~A} / \mathrm{H} 1 \mathrm{~N} 1$ influenza vaccination. PloS One. 2016;11(8):e0160342. https://doi.org/10.1371/journal.pone. 0160342.

124. Chan HJ, Chang JY, Erickson SR, Wang CC. Influenza vaccination among pregnant women in the United States: findings from the 2012-2016 National Health Interview Survey. J Womens Health. 2019;28(7):965-75. https://doi.org/10.1089/jwh.2018. 7139.

125. Office of Disease Prevention and Health Promotion. IID-12.10 Increase the percentage of pregnant women who are vaccinated against seasonal influenza. https:/www.healthypeople.gov/node/ 4660/data details. Accessed 31 July 2019.

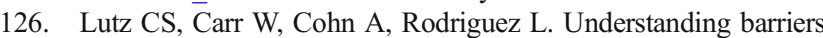
and predictors of maternal immunization: identifying gaps through an exploratory literature review. Vaccine. 2018;36(49):7445-55. https://doi.org/10.1016/j.vaccine.2018.10.046.

127. Wilson RJ, Paterson P, Jarrett C, Larson HJ. Understanding factors influencing vaccination acceptance during pregnancy globally: a literature review. Vaccine. 2015;33(47):6420-9. https://doi.org/10. 1016/j.vaccine.2015.08.046.

128. Eppes C, Wu A, You W, Cameron KA, Garcia P, Grobman W. Barriers to influenza vaccination among pregnant women. Vaccine. 2013;31(27):2874-8. https://doi.org/10.1016/j.vaccine. 2013.04.031.

129. Yuen CY, Tarrant M. Determinants of uptake of influenza vaccination among pregnant women - a systematic review. Vaccine. 2014;32(36):4602-13. https://doi.org/10.1016/j.vaccine.2014.06. 067.

130. Mak DB, Regan AK, Joyce S, Gibbs R, Effler PV. Antenatal care provider's advice is the key determinant of influenza vaccination uptake in pregnant women. Austr N Z J Obstet Gynecol. 2015;55(2):131-7. https://doi.org/10.1111/ajo.12292.

131. Bednarczyk RA, Chamberlain A, Mathewson K, Salmon DA, Omer SB. Practice-, Provider-, and Patient-level interventions to improve preventive care: development of the P3 model. Prev Med Rep. 2018;11:131-8. https://doi.org/10.1016/j.pmedr.2018.06. 009.

132. Palmer S, Pudwell J, Smith GN, Reid RL. Optimizing participation of pregnant women in clinical trials: factors influencing decisions about participation in medication and vaccine trials. J Obstet Gynaecol Can. 2016;38(10):945-54. https://doi.org/10.1016/j. jogc.2016.04.100.

133. Cutland CL, Cunnington M, Olugbosi M, Jones SA, Hugo A, Maharaj K, et al. Lessons learnt from enrolment and follow up of pregnant women and their infants in clinical trials in South Africa, a low-middle income country. Vaccine. 2015;33(47): 6406-12. https://doi.org/10.1016/j.vaccine.2015.08.040. 
134. Wilcox CR, Calvert A, Metz J, Kilich E, MacLeod R, Beadon K, et al. Attitudes of pregnant women and healthcare professionals toward clinical trials and routine implementation of antenatal vaccination against respiratory syncytial virus: a multicenter questionnaire study. Pediatr Infect Dis J. 2019;38(9):944-51. https://doi. org/10.1097/inf.0000000000002384.

135. Top KA, Arkell C, Scott H, McNeil SA, Mannerfeldt J, Ortiz JR, et al. Effect of package insert language on health-care providers' perceptions of influenza vaccination safety during pregnancy. Lancet Global Health. 2016;4(10):e690-1. https://doi.org/10. 1016/s2214-109x(16)30182-6.

136. Beeler JA, Lambach P, Fulton TR, Narayanan D, Ortiz JR, Omer SB. A systematic review of ethical issues in vaccine studies involving pregnant women. Hum Vaccin Immunother. 2016;12(8): 1952-9. https://doi.org/10.1080/21645515.2016.1186312.

137. Krubiner CB, Faden RR, Karron RA, Little MO, Lyerly AD, Abramson JS, et al. Pregnant women \& vaccines against emerging epidemic threats: ethics guidance for preparedness, research, and response. Vaccine. 2019; in press. https://doi.org/10.1016/j. vaccine.2019.01.011

138. McQuaid F, Jones C, Stevens Z, Meddaugh G, O'Sullivan C, Donaldson B, et al. Antenatal vaccination against Group B streptococcus: attitudes of pregnant women and healthcare professionals in the UK towards participation in clinical trials and routine implementation. Acta Obstet Gynecol Scand. 2018;97(3): 330-40. https://doi.org/10.1111/aogs.13288.

139. Goldfarb IT, Jaffe E, James K, Lyerly AD. Pregnant women's attitudes toward Zika virus vaccine trial participation. Vaccine. 2018;36(45):6711-7. https://doi.org/10.1016/j.vaccine.2018.09. 042 .

140. Schwartz DA. Clinical trials and administration of Zika virus vaccine in pregnant women: lessons (that should have been) learned from excluding immunization with the Ebola vaccine during pregnancy and lactation. Vaccines (Basel). 2018;6(4):E81. https://doi. org/10.3390/vaccines6040081.

141. Ellingson MK, Dudley MZ, Limaye RJ, Salmon DA, O'Leary ST, Omer SB. Enhancing uptake of influenza maternal vaccine. Expert Rev Vaccines. 2019;18(2):191-204. https://doi.org/10.1080/ 14760584.2019.1562907.

142. Wong VW, Lok KY, Tarrant M. Interventions to increase the uptake of seasonal influenza vaccination among pregnant women: a systematic review. Vaccine. 2016;34(1):20-32. https://doi.org/10. 1016/j.vaccine.2015.11.020.
143. Stockwell MS, Westhoff C, Kharbanda EO, Vargas CY, Camargo $\mathrm{S}$, Vawdrey DK, et al. Influenza vaccine text message reminders for urban, low-income pregnant women: a randomized controlled trial. Am J Public Health. 2014;104(Suppl 1):e7-12. https://doi. org/10.2105/ajph.2013.301620.

144. Yudin MH, Mistry N, De Souza LR, Besel K, Patel V, Blanco Mejia $\mathrm{S}$, et al. Text messages for influenza vaccination among pregnant women: a randomized controlled trial. Vaccine. 2017;35(5):842-8. https://doi.org/10.1016/j.vaccine.2016.12.002.

145. Regan AK, Bloomfield L, Peters I, Effler PV. Randomized controlled trial of text message reminders for increasing influenza vaccination. Ann Fam Med. 2017;15(6):507-14. https://doi.org/ 10.1370/afm. 2120.

146. Kochhar S, Edwards KM, Ropero Alvarez AM, Moro PL, Ortiz JR. Introduction of new vaccines for immunization in pregnancy programmatic, regulatory, safety and ethical considerations. Vaccine. 2019;37(25):3267-77. https://doi.org/10.1016/j.vaccine. 2019.04.075.

147. Sobanjo-Ter Meulen A, Munoz FM, Kaslow DC, Klugman KP, Omer SB, Vora P, et al. Maternal interventions vigilance harmonization in low- and middle-income countries: stakeholder meeting report; Amsterdam, May 1-2, 2018. Vaccine. 2019;37(20): 2643-50. https://doi.org/10.1016/j.vaccine.2019.03.060.

148. Kochhar S, Clarke E, Izu A, Emmanuel Kekane-Mochwari K, Cutland CL. Immunization in pregnancy safety surveillance in low and middle-income countries- field performance and validation of novel case definitions. Vaccine. 2019;37(22):2967-74. https://doi.org/10.1016/j.vaccine.2019.03.074.

149. Krishnaswamy S, Lambach P, Giles ML. Key considerations for successful implementation of maternal immunization programs in low and middle income countries. Hum Vaccin Immunother. 2019;15(4):942-50. https://doi.org/10.1080/21645515.2018. 1564433.

150. Sobanjo-Ter Meulen A, Abramson J, Mason E, Rees H, Schwalbe $\mathrm{N}$, Bergquist S, et al. Path to impact: a report from the Bill and Melinda Gates Foundation convening on maternal immunization in resource-limited settings; Berlin - January 29-30, 2015. Vaccine. 2015;33(47):6388-95. https://doi.org/10.1016/j.vaccine. 2015.08.047.

Publisher's Note Springer Nature remains neutral with regard to jurisdictional claims in published maps and institutional affiliations. 